Article

\title{
Eco-Efficiency of End-of-Pipe Systems: An Extended Environmental Cost Efficiency Framework for Wastewater Treatment
}

\author{
Xinyue Zhao ${ }^{1}$, Chaofan Zhang ${ }^{2}$ and Shunwen Bai ${ }^{3, *(D)}$ \\ 1 College of Resources and Environment, Northeast Agricultural University, Harbin 150030, China; \\ zhaoxy@neau.edu.cn \\ 2 Yuyang Water Conservancy Bureau, Zhengzhou 450000, China; fancynn@yeah.net \\ 3 State Key Laboratory of Urban Water Resource and Environment, School of Environment, \\ Harbin Institute of Technology, Harbin 150090, China \\ * Correspondence: baishunwen@hit.edu.cn
}

Received: 16 January 2020; Accepted: 6 February 2020; Published: 8 February 2020

\begin{abstract}
As a method for eco-efficiency analysis, environmental cost efficiency (ECE) indicators have been proposed for the end-of-pipe (EOP) systems that referred to the techniques achieving environmental benefit under economic cost. The wastewater treatment plant (WWTP) belongs to the EOP systems; however, few studies used the ECE indicators for the sustainability evaluation. Here, this study first proposed the following processes that had been excluded in the current ECE framework and thus limited the potential application in WWTP: (1) the direct impact of wastewater on receiving water, (2) the migration and transformation of water pollutants affected by the self-purification mechanisms of receiving water. To address the aforementioned processes, this study extended the framework of ECE indicators by means of incorporating the potential growth of microorganisms as the characterization state and integrating the water quality models with the characterization models. To investigate the applicability, a full-scale WWTP was selected as the study case and the eco-efficiency of the increasing levels of sewage treatment was evaluated. The case outcome showed that, with the extended ECE indicators, the analysis of eco-efficiency could be directly related to the specific locations and could determine the specific distance ranges within which the scenarios changing were considered efficient. Moreover, the eco-efficiency could be investigated under more concrete and flexible situations because the extended framework of ECE indicators was able to include more information, such as different types of receiving water or different environmental conditions of certain water body.
\end{abstract}

Keywords: eco-efficiency; life cycle assessment; wastewater treatment; depletion of dissolved oxygen; water quality model

\section{Introduction}

Eco-efficiency analysis enables the assessment of sustainability from combined perspectives of environment and economy and has been increasingly applied to evaluate the performance of waste management systems [1-7]. Among various feasible methods, environmental cost efficiency (ECE) is established specifically for the end-of-pipe (EOP) systems, which refer to the techniques achieving environmental benefit under a certain amount of economic cost [6]. In particular, the pollutant-removal techniques, designed and operated to dispose wastewater or solid waste, exactly belong to the EOP system. The ECE method has been efficiently implemented regarding the optimized management of municipal solid waste [2]. Upon the evaluation of wastewater treatment plants (WWTPs), however, the ECE method has been rarely used. In order to promote the future application in this regard, 
it would be legitimate and necessary to first identify the issues that could limit the effectiveness in application and then seek available solutions.

Environmental impact assessment constitutes an important part of ECE method, where the evaluation outcomes are generated by conducting Life Cycle Assessment (LCA), a standardized and sophisticated method that can quantitatively assess the environmental impacts of techniques, processes or services throughout their entire value chains [8-10]. LCA has been widely used in evaluation of WWTPs-related topics [11-14], offering a great deal of possibility to further perform ECE estimation. Nevertheless, there are inherent problems inside the LCA approach, hindering the evaluation on WWTPs, and this will accordingly limit the effectiveness when applying ECE method.

One major problem lies with the LCA results that have abstract meanings, representing the generic impact without referring to any specific situations; that is to say, the results cannot comprehensively reflect the direct impacts of WWTPs effluents on the receiving water [15,16]. In response to this problem, there have been efforts to investigate the usage of site-specific LCA approach or the regional inventory data in assessing wastewater-related issues [17,18]; however, these studies made little contributions to map the direct impact of WWTPs effluent. In addition, eutrophication impact category has been a key point for the methodological progresses of LCA, involving the development of spatially explicit factors on lake-level or stream-level, spatially differentiated factors regarding different emission sources and the fate model for phosphorus emissions on the continent-scale and country-scale [19-23]. However, these methodological progresses were rarely applied on WWTPs-related issues, despite that eutrophication has been considered a relevant LCA impact category to wastewater.

To overcome the aforementioned problem, efforts should be made to refine the ECE method by means of characterizing the direct effect of wastewater within the phase of environmental impact assessment. A representative effect is the depletion of dissolved oxygen, resulted from the growth of microorganisms encouraged by the emitted organic matter contained in wastewater [24]. Such an effect could seriously endanger the aquatic ecosystems, especially in developing countries, such as China, where large amounts of inland water bodies are suffering from the lack of dissolved oxygen. In addition, considering the dynamic migrating process of water pollutants and the self-purification mechanisms of receiving water, the direct effect of wastewater is influenced by many environmental factors, such as water velocity, water temperatures and downstream distances [25-28]. This promotes the necessity of developing reasonable methods to generate dynamic estimation results that are the function of multiple variables.

To that end, this study extended the framework of ECE method on the basis of characterizing the depletion of dissolved oxygen and capturing the migration and transformation processes of water pollutants in receiving water. The establishment process of the extended ECE framework was described in detail, and a descriptive case analysis was conducted to demonstrate how to use the proposed method to evaluate a real WWTP case.

\section{Methods and Materials}

\subsection{General Scheme of ECE Indicators}

Figure 1 shows the entire framework of ECE indicators. The general scheme of ECE indicators is described in Figure 1a and was defined in the previous study as a form of the ratios of net environmental benefit to net economic cost. ECE indicators are used to calculate the environmental benefit of Alternative 1 over Alternative 2 per additional economic cost [6]. The extended framework, proposed in this present work is demonstrated in Figure 1b. By incorporating the oxygen-depleting potential and the fate of water pollutants, the main contributions of the extended framework were to include the water quality modeling systems and a unique impact category associated with its characterization factors and models within the ECE indicators. The water quality modeling systems are effective tools that could simulate and predict the fate and behaviors of pollutants in a water environment. The impact category was defined as Bacterial Depletion of Oxygen (BDO), representing 
the oxygen-depleting potential which was caused by the growth of microorganisms due to the release of wastewater. The BDO category was in parallel with other impact categories, such as global warming or acidification, and the characterization factors and models were established on the basis of LCA system [29]. Of note, as an indicator designed specifically for LCA, the BDO category is inconsistent with the indicator termed as Biochemical Oxygen Demand, which is used to monitor environmental pollution by representing the total organic content that is available to organisms, plus any chemicals that spontaneously react with $\mathrm{O}_{2}$.

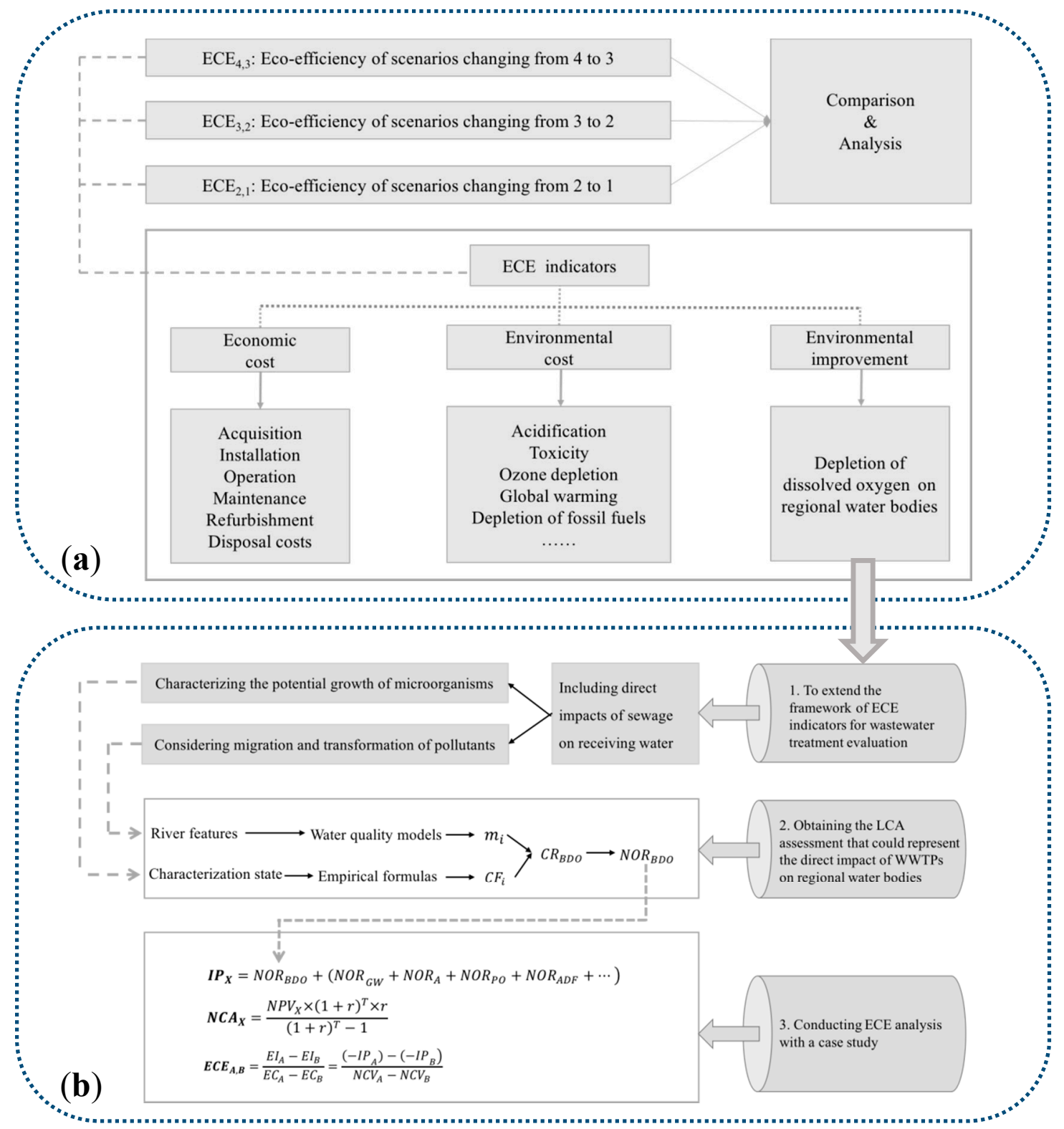

Figure 1. Framework of this study: (a) shows the general scheme for the conduction and comparison of environmental cost efficiency (ECE) indicators between different scenarios; (b) shows the development of the extended ECE indicators in this study.

ECE indicators were determined with Equation (1), by calculating the net environmental improvement per unit economic cost, as defined in previous studies.

$$
E C E_{A, B}=\frac{E I_{A}-E I_{B}}{E C_{A}-E C_{B}}=\frac{\left(-I P_{A}\right)-\left(-I P_{B}\right)}{N C A_{A}-N C A_{B}}
$$


where $E C E_{A, B}$ was the net environmental improvement of scenario A over scenario $\mathrm{B}$ per additional cost, NCA was the discounted net cost, EI was the environmental improvement measured against a null option, and IP was the environmental impact potential based on LCA calculation, which was described by Equations (2) and (3).

$$
\begin{gathered}
I P_{X}=\sum_{j} W_{j} N O R_{C R, j} \\
C R_{i}=\sum_{i} C F_{i} \times m_{i}
\end{gathered}
$$

where $I P_{X}$ represented the total environmental impact for certain scenario $X ; j$ referred to the impact categories; $i$ referred to the substances contributing to the impact categories; $W_{j}$ was the weighting factor; $C F_{i}$ was the characterization factor; $m_{i}$ was the emitted amount; and $N O R_{C R, j}$ was the normalized score of the characterization result for $j$ impact category.

The economic dimension of ECE indicators was calculated with the concept of discounted net cost, which could be quantified by method of the annuity method (Equation (4)).

$$
N C A_{X}=\frac{N P V_{X} \times(1+r)^{T} \times r}{(1+r)^{T}-1}
$$

where $N P V_{x}$ was the net present value; $t$ was the time index; $T$ was the lifetime of scenario $X$; and $r$ was the discount rate.

\subsection{Extended Framework of ECE Indicators}

The extended framework included (1) the characterization of oxygen-depletion potential due to the growth of microorganisms via defining a new impact category and developing its characterization factors and models, and (2) the incorporation of the fate of water pollutants by means of integrating BDO category with water quality models.

\subsubsection{Characterization of Oxygen-Depleting Potential}

Characterization results of BDO impact category was calculated with Equation (3). The characterization factors were calculated as follows:

$$
C F_{i}=\frac{v_{i} / M_{i}}{v_{r e f} / M_{r e f}}
$$

where $v_{i}$ and $v_{\text {ref }}$ represented the potential contribution of one mole of substance $i$ and reference substance $\left(\mathrm{NO}_{3}{ }^{-}\right)$to the bacterial growth, respectively. Substance $i$ referred to water pollutants (COD and TN in this study) that could stimulate the growth of bacteria. $M_{i}$ and $M_{r e f}$ referred to the molar mass of substance $i$ and reference substance $\left(\mathrm{NO}_{3}{ }^{-}\right)$. Moreover, $v_{i}$ and $M_{i}$ were determined on the basis of chemical composition of bacteria with Equation (6).

$$
\mathrm{C}_{n} \mathrm{H}_{a} \mathrm{O}_{b} \mathrm{~N}_{c}+\left(\frac{2 n+0.5 a-1.5 c-b}{2}\right) \mathrm{O}_{2} \rightarrow n \mathrm{CO}_{2}+c \mathrm{NH}_{3}+\left(\frac{a-3 c}{2}\right) \mathrm{H}_{2} \mathrm{O}
$$

where the degradation of one mole of bacterial biomass $\left(C_{n} H_{a} \mathrm{O}_{b} N_{c}\right)$ required $c$ mole of $N$ and $(2 n+$ $0.5 a-1.5 c-b) / 2$ mole of COD.

Accordingly, for the potential contribution to bacterial growth, $v_{N}=1 / c$ and $v_{C O D}=1 /\left(\frac{2 n+0.5 a-1.5 c-b}{2}\right)$.

Bacterial empirical formula was selected to represent the bacterial biomass [30]. These empirical formulas included aerobic bacteria or anaerobic bacteria. Herein, empirical formulas of aerobic bacteria such as $\mathrm{C}_{5} \mathrm{H}_{7} \mathrm{O}_{2} \mathrm{~N}, \mathrm{C}_{7} \mathrm{H}_{12} \mathrm{O}_{4} \mathrm{~N}, \mathrm{C}_{9} \mathrm{H}_{15} \mathrm{O}_{5} \mathrm{~N}$ and $\mathrm{C}_{9} \mathrm{H}_{16} \mathrm{O}_{5} \mathrm{~N}$ were chosen to calculate the characterization factors of $\mathrm{COD}$ and TN. 


\subsubsection{Integration of BDO Category with Water Quality Models}

To capture the migration and transformation of water pollutants in water bodies, water quality models were induced to couple with BDO characterization model. In this way, the dynamic interaction between water pollutants and water bodies could be reflected in ECE indicators.

For rivers with small sizes, one-dimensional water quality models (One-DWQM) could be used to describe the fate of water pollutants [31]. The use of One-DWQM supposed that the concentration of water pollutants only changed in the longitudinal orientation along the river, and the complete mixing of water pollutants could be achieved instantaneously in the emission section.

The differential equation to build One-DWQM is described with Equation (7).

$$
\frac{\partial c}{\partial \mathrm{t}}+u \frac{\partial c}{\partial x}=E \frac{\partial^{2} c}{\partial x^{2}}-k c
$$

After the integral transformation of Equation (7) and the transformation of concentration equivalent into mass equivalent, the emitted amount of substance $i$, the $m_{i}$ defined in Equation (3), could be described with Equation (8).

$$
m_{C O D}(\mathrm{x})=P_{i} \exp \left(-\frac{k_{i} x}{u}\right)
$$

where $x$ represented the distance from emission point to the downstream water body that was under evaluation; $k_{i}$ was the self-purification coefficients substance $i ; u$ was the water velocity of receiving water bodies; and $P_{i}$ was the average material mass per unit time for substance $i$.

For rivers having bigger sizes with a width more than $200 \mathrm{~m}$, two-dimensional water quality models (Two-DWQM) were more applicable [32]. The concentration of water pollutants was supposed to change in the longitudinal and horizontal directions. Only in the vertical direction, water pollutants were supposed to be in uniform distribution.

The differential equation to build Two-DWQM was described with Equation (9).

$$
\frac{\partial c}{\partial \mathrm{t}}+u_{x} \frac{\partial c}{\partial x}+u_{y} \frac{\partial c}{\partial y}=M_{x} \frac{\partial^{2} c}{\partial x^{2}}+M_{y} \frac{\partial^{2} c}{\partial y^{2}}-k c
$$

After the integral transformation of Equation (8) and the transformation of concentration equivalent into mass equivalent, the emitted amount of substance $i$, the $m_{i}$ defined in Equation (3), would be described with Equation (9).

$$
m_{i}(\mathrm{x}, \mathrm{y})=W_{i} \times \exp \left(-k \frac{x}{86400 u_{x}}\right) \times 1 / H \times \sqrt{\pi M_{y} x u_{x}} \times\left[\exp \left(-\frac{u_{x} y^{2}}{4 M_{y} x}\right)+\exp \left(-\frac{u_{x}(2 B-y)^{2}}{4 M_{y} x}\right)\right]
$$

where $x, k_{i}, u$ and $W_{i}$ were the same parameters defined for Equation (8); y was the horizontal distance from emission point to downstream impact point; $u_{x}$ and $u_{y}$ were water velocities along the longitudinal and horizontal orientation of receiving water; $M_{x}$ and $M_{y}$ were longitudinal and horizontal dispersion coefficients; $H$ was the average depth of receiving water; and $B$ was the width of receiving water.

\subsection{Application of the Extended Framework to a WWTP Case}

\subsubsection{Case Description}

The case study was based on a full-scale WWTP, which is located in Northeast China. According to different effluent treatment requirements, four scenarios were defined, following as scenario-1 (tertiary treatment), scenario-2 (intermediate treatment), scenario-3 (basic treatment) and scenario-4 (no treatment). No treatment scenario meant that wastewater discharged into receiving water without any pretreatment. The basic treatment scenario was designed to degrade organic matter from wastewater. The intermediate treatment scenario was needed when enhanced-nutrients removal was 
required. To achieve the goals of reusing effluent or protecting a recreational water body, tertiary treatment scenario was required to further remove water pollutants.

For investigation, the WWTP was supposed to be built on the banks of two receiving river cases. The first case was one reach of the Ashihe river located in Northeast China. This river reach had a small size, and thereby the One-DWQM was applicable. Another case was one reach of the Harbin mainstay of Songhua river located in China, with a length of $16.25 \mathrm{~km}$, an average width of $450 \mathrm{~m}$ and an average depth of $2.3 \mathrm{~m}$. For this river case with bigger size, the Two-DWQM was applicable. More information concerning with the selected river reaches were described in Tables S3 and S4.

In this study, eco-efficiency of the increasing wastewater treatment levels was evaluated with ECE indicators. Three types of ECE indicators were obtained: $\mathrm{ECE}_{4,3}, \mathrm{ECE}_{3,2}$ and $\mathrm{ECE}_{2,1}$. Specifically, $\mathrm{ECE}_{4,3}$ represented the eco-efficiency of increasing treatment levels from scenario-4 to scenario-3; $\mathrm{ECE}_{3,2}$ represented the shift from scenario-3 to scenario-2; and $\mathrm{ECE}_{2,1}$ represented the shift from scenario-2 to scenario-1.

\subsubsection{Evaluation of Environmental Impact Potential}

LCA was conducted for the environmental impact assessment of ECE indicators. The goal of the case was to assess the potential environmental impact of each treatment scenario. Functional unit for the WWTP was $10,000 \mathrm{~m}^{3}$ of effluent. Study scope was the operational stage of the WWTP, and the system boundary took into account the treatment of wastewater, electricity consumption, chemicals manufacture and transportation, and waste activated sludge processing.

For inventory analysis of each scenario, input elements included electricity, inorganic chemicals and PAM-acrylonitrile. Emissions associated with air, solid and liquid phases were identified as output elements. For air phases, major output elements included carbon dioxide and nitrous oxide. Bio-sludge, tertiary precipitation, phosphorus precipitation and pretreatment solid waste were regarded as the main contributors to the solid phase. With respect to the liquid phase, chemical oxygen demand (COD), total nitrogen (TN) and total phosphorus (TP) were determined as the main water pollutants. More information about the input and output of each scenario is described in Tables S1 and S2.

During life cycle impact assessment (LCIA), inventory data were converted into environmental impact scores within different impact categories. The selected impact categories included photochemical oxidation (PO), global warming (GW), abiotic depletion of fossil fuels (ADF), abiotic depletion of elements (ADE), acidification (A), freshwater aquatic eco-toxicity (FAET), human toxicity (HT), ozone depletion (OD) and biological depletion of oxygen (BDO). BDO was the impact category which was defined in the above section. Characterization factors and models for impact categories except BDO were obtained from the literature [29], and the characterization results of the BDO category were calculated on the basis of the abovementioned equations. Normalization step in LCIA was adopted to convert the characterization results with unique category units into non-dimensional normalized scores [33]. Same weight was assigned to each impact category, for ease of interpretation.

\subsubsection{Economic Analysis}

In this case, the total cost of increasing treatment levels included acquisition, installation, operation, maintenance, refurbishment and disposal costs throughout the lifetime. The lifetime of the tanks and buildings in the WWTP was assumed to be 30 years, while that of the equipment and machines was assumed to be 15 years. A hypothesized discounting rate of $5 \%$ (at constant prices) was used in this case.

\subsubsection{Data Processing}

A calculation model of ECE indicators was formed by combining the general scheme (Figure 1a) and the extended framework (Figure 1b). The modeling input data included the inventory data of the four scenarios (Table S2), the empirical formulas of aerobic bacteria or anaerobic bacteria (see Section 2.2.1), the environmental characteristics of the evaluated reach of the Ashihe river and the 
Songhua river (Tables S3 and S4) and the lifetime of WWTP case associated with the discounting rate (see Section 2.3.3). The modeling output data included the characterization factors of BDO category, the annuity values for all scenarios, the normalized scores across the four scenarios for impact categories (GW, A, PO, ADF, ADE, HT, FAET and OD), the normalized scores for BDO category changing along the longitudinal orientation (based on the Ashihe river), the normalized scores for BDO category changing along the both the longitudinal and horizontal orientations (based on Songhua river), and the final ECE results in forms of $\mathrm{ECE}_{4,3}, \mathrm{ECE}_{3,2}$ and $\mathrm{ECE}_{2,1}$ for eco-efficiency analysis.

\section{Results}

\subsection{Environmental and Economic Assessment}

Environmental impact assessment was conducted through LCA analysis. For each scenario, environmental impact was first evaluated within every impact category except BDO. Table S5 shows the normalization results of each impact category. Results showed that, with the increasing levels of wastewater treatment requirement (from scenario-4 to scenario-1), normalization results for each impact category were increased, indicating that the enhanced removal of water pollutants would add environmental load on these environmental indicators.

For the BDO category, normalization results were obtained to represent the environmental impact of effluents on receiving water, via the integration of the characterization factors of water pollutants and the dynamic changing mass of emitted substance. By means of characterizing the potential growth of aerobic bacteria, characterization factors of COD and TN were calculated. As shown in Table S6, the average $W P_{C O D}$ and $W P_{T N}$ were 0.24 and 4.43 , respectively.

Due to the self-purifying mechanism of receiving water, the mass of emitted substance changes with the different downstream areas; and thereby, the environmental impact of water pollutants on different downstream areas would also change. Through incorporating water quality models into characterization models, correspondence between normalization results of BDO category and different downstream distances could be obtained. Regarding the small river case (the selected reach of the Ashihe river), Table S7 shows the changing BDO normalization results along the longitudinal orientation. For the bigger river case (the selected reach of Harbin mainstay of Songhua river), Tables S8-S11 shows the changing BDO normalization results of each scenario along the longitudinal and horizontal orientation. In addition, with respect to the economic evaluation, the annuity values of the WWTP case were 19,000, 14,100, 11,800 and 1000 Yuan for scenario-1, scenario-2, scenario-3 and scenario-4, respectively.

\subsection{Eco-Efficiency Analysis Using One-DWQM for the Ashihe River Case}

After obtaining the evaluation data on both environmental and economic dimensions for each scenario, ECE indicators over the scenarios changing were able to be calculated in forms of $\mathrm{ECE}_{4,3}$, $\mathrm{ECE}_{3,2}$ and $\mathrm{ECE}_{2,1}$. Figure 2 shows the ECE evaluation results for the WWTP case that was supposed to be built on the bank of the small river (Ashihe river). Positive value means that the scenario changing from one to another can be considered efficient.

With regard to the overall comparison between $\mathrm{ECE}_{4,3}, \mathrm{ECE}_{3,2}$ and $\mathrm{ECE}_{2,1}$ at each distance, $\mathrm{ECE}_{3,2}$ had the highest result, whereas $\mathrm{ECE}_{2,1}$ was the lowest. This indicated that increasing disposal requirement from the intermediate level to the tertiary level was less efficient than the increase from the basic level to the intermediate level.

All the three ECE indicators showed decreasing trends, along with the increase of the distance from the downstream area to the emission point. However, the decrease ranges were different. From 0 to $200 \mathrm{~km}$, for example, the decrease range of $\mathrm{ECE}_{3,2}$ was almost 13 times higher than $\mathrm{ECE}_{2,1}$. The downward trend experienced a process from positive value to zero and from zero to negative value. This process reflected the fact that the eco-efficiency for scenarios changing was not a static single value, but a dynamic value which changed over distance. Within a given range, the eco-efficiency 
could be considered efficient, whereas inefficient beyond the range. Taking scenarios changing from scenario-2 to scenario- 1 as an example, positive $\mathrm{ECE}_{2,1}$ were obtained when the downstream distance was less than $10 \mathrm{~km}$. This indicated that, for the downstream area that was more than $10 \mathrm{~km}$ away from emission point, it could not be considered efficient if disposal requirement was tightened from the intermediate level to the tertiary level.

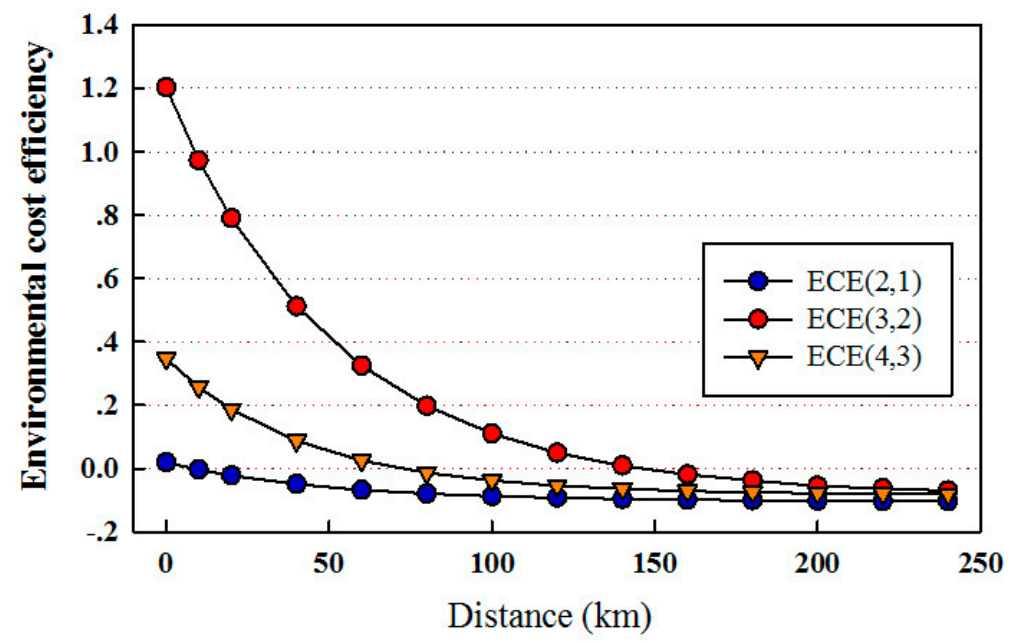

Figure 2. ECE evaluation results for the WWTP case that was supposed to be built on the bank of small river (Ashihe river).

\subsection{Eco-Efficiency Analysis Using Two-DWQM for Songhua River Case}

Figures 3 and 4 show the eco-efficiency analysis for the WWTP case that is supposed to be built on the bank of a bigger river (Songhua river). By incorporating the Two-DWQM, the migration and transformation of water pollutants was reflected by the ECE results, and the results changed along both longitudinal and horizontal orientation. On the basis of Figure 3, it demonstrated the estimation of ECE results within different river areas. For example, within the river area (Y: 0 20 m, X: 0 3000 m), $\mathrm{ECE}_{4,3}$ results ranged from 0.25 to $0.41, \mathrm{ECE}_{3,2}$ results ranged from 0.15 to 0.26 and $\mathrm{ECE}_{2,1}$ results ranged from 0.02 to 0.04 , respectively.

Using Figure 4 enables us to investigate the specific changing trends of ECE results along longitudinal orientation $(\mathrm{X})$ at different horizontal sections $(\mathrm{Y})$. Four horizontal sections $(\mathrm{Y}=0 \mathrm{~m}$, $\mathrm{Y}=50 \mathrm{~m}, \mathrm{Y}=100 \mathrm{~m}$ and $\mathrm{Y}=150 \mathrm{~m}$ ) were selected. Results showed that ECE indicators showed different changing trends at different horizontal sections. For instance, at the horizontal section of $Y$ $=0 \mathrm{~m}, \mathrm{ECE}_{4,3}$ showed the downward trend, along with the increase of $\mathrm{X}$, with the highest value of 0.41 when $X=0 \mathrm{~km}$. At the section of $Y=50 \mathrm{~m}, \mathrm{ECE}_{4,3}$ increased at first and then descended with the further increase of $X$. At the sections of $Y=100 \mathrm{~m}$ and $Y=150 \mathrm{~m}, \mathrm{ECE}_{4,3}$ showed gradual uptrends, with faster growth and higher values at the section of $Y=100 \mathrm{~m}$.

At the same longitudinal distance $(X)$, different results of ECE indicators were obtained at different horizontal sections $(Y)$. The longer distance from horizontal section to the river bank, the lower results of ECE indicators observed. For example, at the identical longitudinal orientation of $X=10 \mathrm{~km}$, the $\mathrm{ECE}_{4,3}$ results decreased from 0.12 to 0.002 when horizontal sections increased from $\mathrm{Y}=0 \mathrm{~m}$ to $\mathrm{Y}=150 \mathrm{~m}$. This data trend indicated that the eco-efficiency of increasing effluent disposal requirement would become lower if a more distant horizontal location was selected for investigation.

At different horizontal sections (Y), for the scenarios changing from one another, it could be considered efficient within different longitudinal distance ranges. With the longer distance from the horizontal section to the river bank, the scenarios' change was considered efficient within the smaller longitudinal ranges. At the section of $Y=0 \mathrm{~m}, \mathrm{ECE}_{2,1}$ showed positive efficiency within the range from $X=0 \mathrm{~km}$ to $X=12 \mathrm{~km}$. However, at the section of $Y=150 \mathrm{~m}, \mathrm{ECE}_{2,1}$ showed little efficiency within any longitudinal distance ranges. 


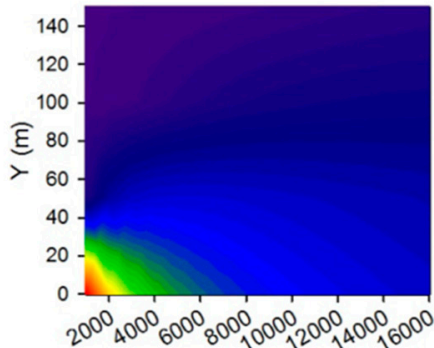

$\mathrm{X}(\mathrm{m})$

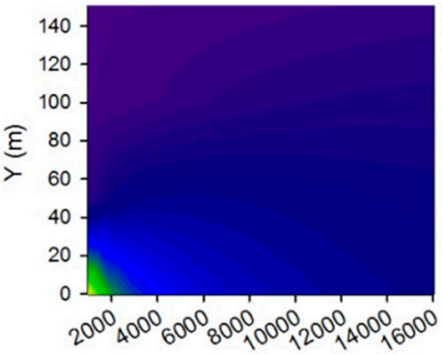

$\mathrm{X}(\mathrm{m})$

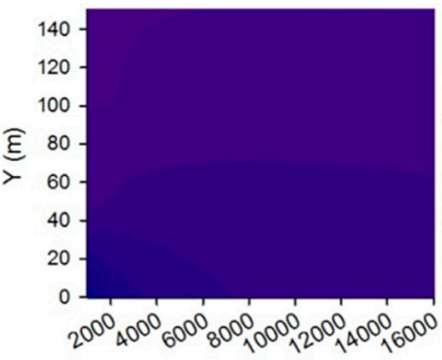

$\mathrm{X}(\mathrm{m})$

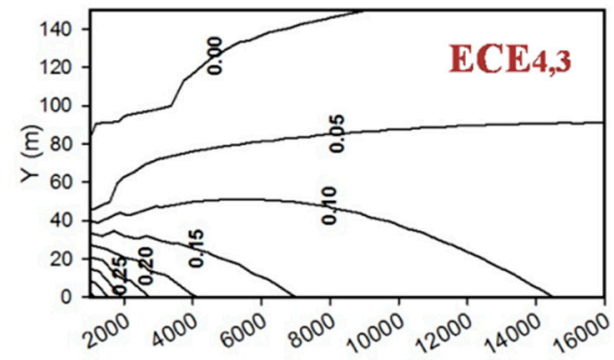

$\mathrm{X}(\mathrm{m})$
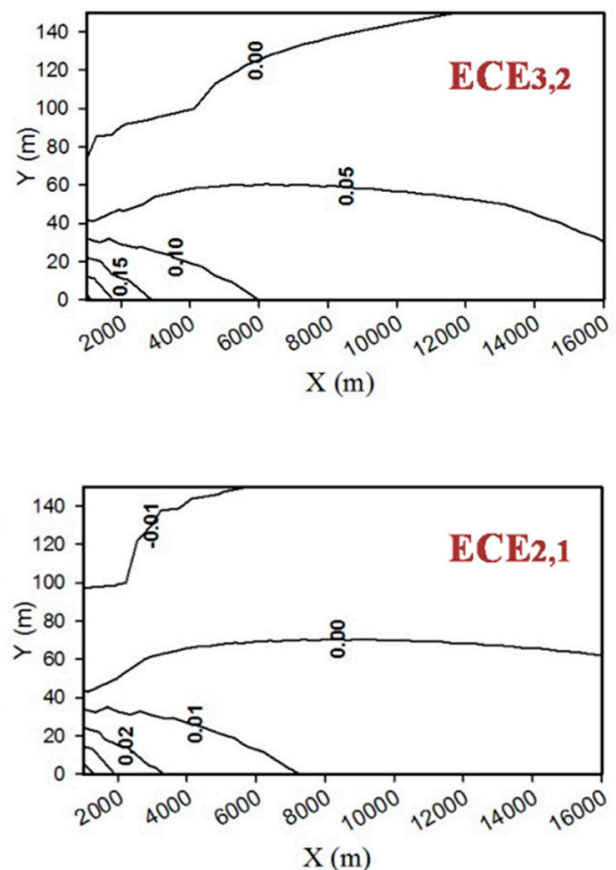

Figure 3. Estimation of ECE results within different river areas $(x, y)$.
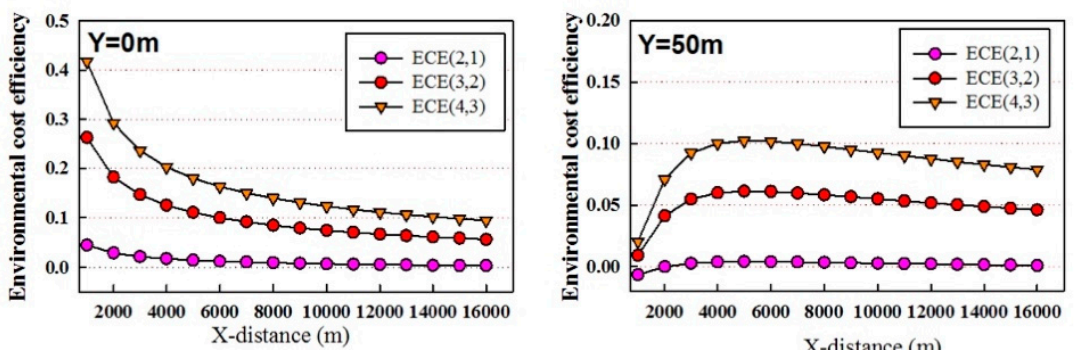

X-distance (m)

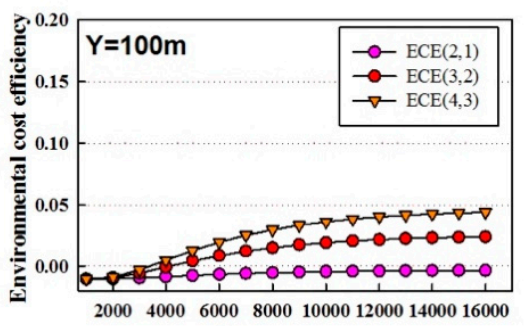

X-distance (m)

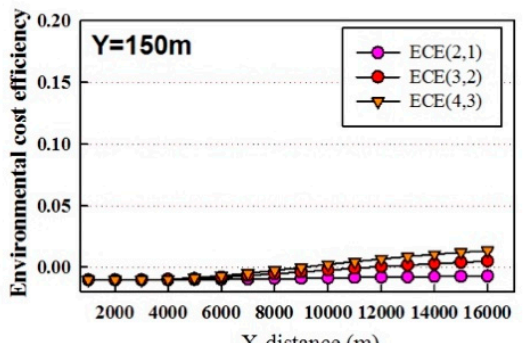

Figure 4. The eco-efficiency analysis for the WWTP case that was supposed to be built on the bank of a bigger river (Songhua river). 


\section{Discussion}

The present study presents an extended framework which aims to deepen the use of eco-efficiency analysis in the field of wastewater treatment. Unlike previous eco-efficiency studies of WWTPs which focused on improving uncertainty analysis [34], including external costs [35], incorporating sustainable values [36], integrating with data envelopment analysis [37] and providing benchmark analysis [38], this extended framework of ECE indicator aimed to incorporate the regional impacts of wastewater into the environmental dimension of eco-efficiency. By means of characterizing the potential growth of microorganisms and integrating water quality models with LCA characterization model, the extended ECE indicators were able to characterize the depletion of dissolved oxygen and capture the water pollutants' migration and transformation processes in receiving water.

A principal function of the extended ECE indicators was to enable the determination of a specific distance range in which the paradigm shift of WWTP could be considered efficient. For instance, positive $\mathrm{ECE}_{2,1}$ was obtained within the distance range from 0 to $10 \mathrm{~km}$ (Figure 2), indicating an efficient paradigm shift within this distance range in terms of the transition from the intermediate level to tertiary level. The main cause of the function was the integration of water quality models into the environmental impact assessment of ECE indicators. In this way, site-specific information (i.e., water velocity or downstream distance) was embedded into the ECE indicators, making the estimation results have location-specific meanings. For example, in terms of the paradigm shift from the no treatment to the basic treatment, the $\mathrm{ECE}_{4,3}$ result was 0.0923 at the orientation of $\mathrm{X}=10 \mathrm{~km}$ and $\mathrm{Y}=50 \mathrm{~m}$ (Figure 4), indicating that the environmental benefit per additional cost was 0.0923 with respect to the specific location, which is $10 \mathrm{~km}$ away from the emission point at longitudinal orientation $(X)$ and $50 \mathrm{~m}$ away at horizontal orientation (Y).

Achieving this function was different with the general calculation framework of the ECE indicators, which did not include any site-specific information and could only generate site-generic results. Using the general ECE framework, the comparison between alternatives was conducted in a generalizable environment. Notably, the estimation results without referring to any specific locations were applicable to the large-scale environmental categories, such as global warming, but not favorable to the regional-scale categories, such as the depletion of oxygen in receiving water $[17,39]$. Thus, the purpose of the present work was to supplement the general ECE calculation framework, in order to estimate the impacts of water pollutants more accurately and make the ECE indicators more applicable to investigate the paradigm shifts in wastewater treatment.

The depletion of dissolved oxygen was characterized in the environmental dimension of the ECE indicators in this study. The potential growth of aerobic microorganism was selected as the characterization state for the BDO impact category. In fact, the growth of aerobic microorganism did not represent the real damage of water pollutants to the receiving water, but represented a factor that would cause damage to the receiving water. Choosing aerobic microorganism as characterization state was a way of simplifying the process of depletion of dissolved oxygen within the LCA framework, aiming to distinguish from the process of eutrophication potential that chose biomass production as characterization state. Moreover, the determination of characterization state depended on the specific situation of the eco-efficiency analysis case. For the selected WWTP in this study, it was located in China, where the aquatic environments were suffering great pressure from the formation of black and odorous states due to organic pollutants [40]. This was one of the reasons why the depletion of dissolved oxygen was determined to be the characterization state here.

More flexible eco-efficiency analysis in wastewater treatment was allowed due to the incorporation of water quality models into ECE indicators. Specifically, incorporating water quality models meant that the characteristics of receiving water were considered. The eco-efficiency analysis could be conducted in light of different types of receiving water or different conditions of certain receiving water. For Alternative 1 over Alternative 2, it allowed us to investigate the eco-efficiency under more concrete situations. Nevertheless, conducting flexible eco-efficiency analysis inevitably involved more necessary information and more complex calculations. For the incorporation of One-DWQM, 
the longitudinal parameters relevant to the downstream water body were the necessary information for the eco-efficiency analysis. Both longitudinal and horizontal parameters were indispensable for the incorporation of Two-DWQM. Moreover, a three-dimensional water quality model might be needed in the future to obtain a more accurate eco-efficiency analysis, which means that the vertical parameters of receiving water would become indispensable. There were uncertainties in the collection of these parameters of receiving water, and these uncertainties would increase the uncertainties of the eco-efficiency analysis.

\section{Conclusions}

This paper extended the framework of ECE indicators for the eco-efficiency analysis in wastewater treatment plants. In the environmental dimension of ECE indicators, the potential growth of microorganisms was defined as the characterization state, and the water quality models were incorporated to capture the migration and transformation of water pollutants. A case study of a full-scale WWTP in Northeast China was carried out, using the extended framework of ECE, and suggested that the extended ECE calculation framework could estimate the impacts of water pollutants more accurately and make the ECE indicators more applicable to investigate the paradigm shifts in wastewater treatment. With the extended ECE indicators, we could obtain the results representing the eco-efficiency that was related to specific locations, determine the distance ranges within which the scenarios' change could be considered efficient and investigate the eco-efficiency under more concrete and flexible situations. However, collecting the parameters that were related to receiving water bodies might lead to some limitations and uncertainties, which will be explored in future studies.

Supplementary Materials: The following are available online at https://www.mdpi.com/2073-4441/12/2/454/s1. Table S1: Effluent quality of different effluent disposal levels, Table S2: Input and output elements of different scenarios, Table S3: Parameters of one selected reach of Ashihe river, Table S4: Parameters of one selected reach of Songhua river, Table S5: Normalized results for each impact category of each scenario, Table S6: The calculated characterization factors for COD and TN, Table S7: Changing BDO normalization results along the longitudinal orientation (Ashihe river), Table S8: Changing BDO normalization results of scenario-4 (Songhua river), Table S9: Changing BDO normalization results of scenario-3 (Songhua river), Table S10: Changing BDO normalization results of scenario-2 (Songhua river), Table S11: Changing BDO normalization results of scenario-1 (Songhua river).

Author Contributions: X.Z. and C.Z. performed the experiments and wrote the paper; S.B. contributed to the discussion and analyzed the experiments. All authors have read and agreed to the published version of the manuscript.

Funding: This research was funded by China Postdoctoral Science Foundation (AUGA4130905019) and National Outstanding Postdoctoral Fund (AUGA4150000419) to Shunwen Bai, and Academic Backbone Project of Northeast Agricultural University (18YJXG11) to Xinyue Zhao.

Conflicts of Interest: The authors declare no competing financial interests.

\section{References}

1. Huppes, G.; Ishikawa, M. A framework for quantified eco-Efficiency analysis. J. Ind. Ecol. 2005, 9, $25-41$. [CrossRef]

2. Shao, L.; Yu, X.; Feng, C. Evaluating the eco-efficiency of China's industrial sectors: A two-Stage network data envelopment analysis. J. Environ. Manag. 2019, 247, 551-560. [CrossRef] [PubMed]

3. Mah, C.M.; Fujiwara, T.; Ho, C.S. Life cycle assessment and life cycle costing toward eco-Efficiency concrete waste management in Malaysia. J. Clean. Prod. 2018, 172, 3415-3427. [CrossRef]

4. Shonnard, D.R.; Kicherer, A.; Saling, P. Industrial applications using BASF eco-Efficiency analysis: Perspectives on green engineering principles. Environ. Sci. Technol. 2003, 37, 5340-5348. [CrossRef]

5. Bohne, R.A.; Brattebø, H.; Bergsdal, H. Dynamic Eco-Efficiency Projections for Construction and Demolition Waste Recycling Strategies at the City Level. J. Ind. Ecol. 2008, 12, 52-68. [CrossRef]

6. Hellweg, S.; Doka, G.; Finnveden, G.; Hungerbühler, K. Assessing the Eco-Efficiency of End-of-Pipe Technologies with the Environmental Cost Efficiency Indicator. J. Ind. Ecol. 2005, 9, 189-203. [CrossRef] 
7. Ingaramo, A.; Heluane, H.; Colombo, M.; Cesca, M. Water and wastewater eco-Efficiency indicators for the sugar cane industry. J. Clean. Prod. 2009, 17, 487-495. [CrossRef]

8. Hellweg, S.; Mila i Canals, L. Emerging approaches, challenges and opportunities in life cycle assessment. Science 2014, 344, 1109-1113. [CrossRef]

9. Guinee, J.B.; Heijungs, R.; Huppes, G.; Zamagni, A.; Masoni, P.; Buonamici, R.; Ekvall, T.; Rydberg, T. Life cycle assessment: Past, present, and future. Environ. Sci. Technol. 2011, 45, 90-96. [CrossRef]

10. Ross, S.; Evans, D. Use of life cycle assessment in environmental management. Environ. Manag. 2002, 29, 132-142. [CrossRef]

11. Bai, S.; Zhao, X.; Wang, D.; Zhang, X.; Ren, N. Engaging multiple weighting approaches and Conjoint Analysis to extend results acceptance of life cycle assessment in biological wastewater treatment technologies. Bioresour. Technol. 2018, 265, 349-356. [CrossRef] [PubMed]

12. Zhao, X.; Bai, S.; Li, C.; Yang, J.; Ma, F. Bioaugmentation of atrazine removal in constructed wetland: Performance, microbial dynamics, and environmental impacts. Bioresour. Technol. 2019, 289, 121618. [CrossRef] [PubMed]

13. Zhao, X.; Bai, S.; Zhang, X. Establishing a decision-support system for eco-Design of biological wastewater treatment: A case study of bioaugmented constructed wetland. Bioresour. Technol. 2019, 274, 425-429. [CrossRef] [PubMed]

14. Bai, S.; Zhang, X.; Xiang, Y.; Wang, X.; Zhao, X.; Ren, N. HIT. WATER scheme: An integrated LCA-Based decision-Support platform for evaluation of wastewater discharge limits. Sci. Total Environ. 2019, 655, 1427-1438. [CrossRef]

15. Corominas, L.; Foley, J.; Guest, J.; Hospido, A.; Larsen, H.; Morera, S.; Shaw, A. Life cycle assessment applied to wastewater treatment: State of the art. Water Res. 2013, 47, 5480-5492. [CrossRef]

16. Zang, Y.; Li, Y.; Wang, C.; Zhang, W.; Xiong, W. Towards more accurate life cycle assessment of biological wastewater treatment plants: A review. J. Clean. Prod. 2015, 107, 676-692. [CrossRef]

17. Bai, S.; Wang, X.; Huppes, G.; Zhao, X.; Ren, N. Using site-Specific life cycle assessment methodology to evaluate Chinese wastewater treatment scenarios: A comparative study of site-generic and site-Specific methods. J. Clean. Prod. 2017, 144, 1-7. [CrossRef]

18. Hernández-Padilla, F.; Margni, M.; Noyola, A.; Guereca-Hernandez, L.; Bulle, C. Assessing wastewater treatment in Latin America and the Caribbean: Enhancing life cycle assessment interpretation by regionalization and impact assessment sensibility. J. Clean. Prod. 2017, 142, 2140-2153. [CrossRef]

19. Basset-Mens, C.; Anibar, L.; Durand, P.; van der Werf, H.M.G. Spatialised fate factors for nitrate in catchments: Modelling approach and implication for LCA results. Sci. Total Environ. 2006, 367, 367-382. [CrossRef]

20. Gallego, A.; Rodriguez, L.; Hospido, A.; Moreira, M.T.; Feijoo, G. Development of regional characterization factors for aquatic eutrophication. Int. J. Life Cycle Assess. 2010, 15, 32-43. [CrossRef]

21. Azevedo, L.B.; Henderson, A.D.; van Zelm, R.; Jolliet, O.; Huijbregts, M.A.J. Assessing the Importance of Spatial Variability versus Model Choices in Life Cycle Impact Assessment: The Case of Freshwater Eutrophication in Europe. Environ. Sci. Technol. 2013, 47, 13565-13570. [CrossRef]

22. Helmes, R.J.K.; Huijbregts, M.A.J.; Henderson, A.D.; Jolliet, O. Spatially explicit fate factors of phosphorous emissions to freshwater at the global scale. Int. J. Life Cycle Assess. 2012, 17, 646-654. [CrossRef]

23. Struijs, J.; Beusen, A.; de Zwart, D.; Huijbregts, M. Characterization factors for inland water eutrophication at the damage level in life cycle impact assessment. Int. J. Life Cycle Assess. 2011, 16, 59-64. [CrossRef]

24. Bai, S.; Wang, X.; Zhao, X.; Ren, N. Characterizing water pollution potential in life cycle impact assessment based on bacterial growth and water quality models. Water 2018, 10, 1621. [CrossRef]

25. González, S.O.; Almeida, C.; Calderón, M.; Mallea, M.; González, P. Assessment of the water self-Purification capacity on a river affected by organic pollution: Application of chemometrics in spatial and temporal variations. Environ. Sci. Pollut. R 2014, 21, 10583-10593. [CrossRef]

26. Vagnetti, R.; Miana, P.; Fabris, M.; Pavoni, B. Self-Purification ability of a resurgence stream. Chemosphere 2003, 52, 1781-1795. [CrossRef]

27. Schnoor, J.L. Environmental Modeling: Fate and Transport of Pollutants in Water, Air, and Soil; John Wiley and Sons: Hoboken, NJ, USA, 1996.

28. Ostroumov, S. On some issues of maintaining water quality and self-Purification. Water Resour. 2005, 32, 305-313. [CrossRef] 
29. Guinée, J.B. Handbook on life cycle assessment operational guide to the ISO standards. Int. J. Life Cycle Assess. 2001, 7, 311-313. [CrossRef]

30. Rittmann, B.E.; McCarty, P.L. Environmental Biotechnology: Principles and Applications; Tata McGraw-Hill Education: New York, NY, USA, 2012.

31. Lap, B.Q.; Mori, K.; Inoue, E. A one-Dimensional model for water quality simulation in medium- and small-Sized rivers. Paddy Water Environ. 2007, 5, 5-13. [CrossRef]

32. Covelli, P.; Marsili-Libelli, S.; Pacini, G. SWAMP: A two-Dimensional hydrodynamic and quality modeling platform for shallow waters. Numer. Methods Part Differ. Equ. 2002, 18, 663-687. [CrossRef]

33. Sleeswijk, A.W.; van Oers, L.F.; Guinee, J.B.; Struijs, J.; Huijbregts, M.A. Normalisation in product life cycle assessment: An LCA of the global and European economic systems in the year 2000. Sci. Total Environ. 2008, 390, 227-240. [CrossRef] [PubMed]

34. Dong, X.; Zhang, X.; Zeng, S. Measuring and explaining eco-Efficiencies of wastewater treatment plants in China: An uncertainty analysis perspective. Water Res. 2017, 112, 195-207. [CrossRef] [PubMed]

35. Garcilaso, L.; Gaines, W.; Barkdoll, B. Ecoefficiency Analysis of Existing Industrial Wastewater Treatment: How to Include the External Costs to the Environment. World Environmental and Water Resource Congress. 2006, 867-869. [CrossRef]

36. Henriques, J.; Catarino, J. Sustainable value-An energy efficiency indicator in wastewater treatment plants. J. Clean. Prod. 2017, 142, 323-330. [CrossRef]

37. Lorenzo-Toja, Y.; Vã, Z.-R.I.; Chenel, S.; Marã-N-Navarro, D.; Moreira, M.T.; Feijoo, G. Eco-Efficiency analysis of Spanish WWTPs using the LCA + DEA method. Water Res. 2015, 68, 651-666. [CrossRef]

38. Lorenzo-Toja, Y.; Vã, Z.-R.I.; Amores, M.J.; Termes-Rifã, M.; Marã-N-Navarro, D.; Moreira, M.T.; Feijoo, G. Benchmarking wastewater treatment plants under an eco-Efficiency perspective. Sci. Total Environ. 2016, 566-567, 468-479. [CrossRef]

39. Renou, S.; Thomas, J.S.; Aoustin, E.; Pons, M.N. Influence of impact assessment methods in wastewater treatment LCA. J. Clean. Prod. 2008, 16, 1098-1105. [CrossRef]

40. Bai, S.; Ren, N.; You, S.; Zhao, X.; Li, Y.; Wang, X. Modeling the oxygen-Depleting potential and spatially differentiated effect of sewage organics in life cycle assessment for wastewater management. Sci. Total Environ. 2019, 655, 1071-1080. [CrossRef] 